\title{
QUANDO SE QUER AGIR, NÃO BASTA SOMENTE QUERER O BEM: INFLUXO HEGELIANO SOBRE UM LEVINAS POLÍTICO
}

Marcelo Fabri

Universidade Federal de Santa Maria

RESUMO: O artigo parte de Hegel para mostrar em que medida Levinas está atento às lições hegelianas sobre ética, política e história universal. Se, como afirma Hegel, "na história universal, resulta das ações humanas algo além do que foi intencionado", Levinas, embora crítico contundente da idolatria hegeliana do Estado, reconhece que a moral subjetiva é insuficiente para se pensar as relações entre o eu e a totalidade. Não se trata, todavia, de compreender os acontecimentos históricos violentos a partir das astúcias da razão, mas de propor um pensamento ético-político que nunca se põe em consonância com as violências do mundo.

Palavras-chave: Ética, Justiça, Totalidade, Fenomenologia, Política.

ABSTRACT: The article begins with Hegel to show in to which extent Levinas is attentive to Hegelian lessons on ethics, politics and universal history. If, as Hegel asserts, "in human history, out of human actions results something beyond of what was intended", Levinas, while a striking critic of the Hegelian idolatry of the State, recognizes that subjective morality is insufficient to think of the relations between self and the totality. It is not, however, a question of understanding violent historical events based on the wiles of reason, it is instead of proposing an ethical-political thinking that is never in line with the violence of the world.

Keywords: Ethics, Totality, Phenomenology, Politics. 
Levinas é conhecido, em boa medida, por suas críticas a Hegel e, consequentemente, ao conceito de totalidade. Vale lembrar, no entanto, que, na perspectiva levinasiana, o conceito de totalidade é fundamental para se compreender a relação da ética com a política. A esse respeito, uma importante lição, vinda de Hegel, é esta: sempre podemos ser enganados por uma moral puramente subjetiva ou formal, aquela que ainda não compreendeu sua inevitável participação na totalidade, sobretudo em sentido político. Tomemos a proposição: "Na história universal, resulta das ações humanas algo além do que foi intencionado (...). Quando se quer agir, não basta querer somente o bem, precisa-se saber se isto ou aquilo é o bem" ${ }^{1}$. Sempre que agimos em consonância com nossas intenções, forças exteriores tomam conta daquilo que tivemos intenção de realizar, trazendo consequências imprevisíveis a nosso agir². Hegel lembra um antigo ditado: "Quando uma pedra sai da mão que a lançou, ela cai sob o poder do diabo"3. Levinas, por sua vez, afirma que somos responsáveis por acontecimentos que fogem ao nosso controle, a despeito de nossas boas intenções, mas, em vez de pensar esse problema apelando para a totalidade ético-política de um Estado, propõe que é preciso levar em conta uma inteligibilidade que, a uma só vez, questiona e condiciona a totalidade. Por que criticar a totalidade? Porque nunca somos suficientemente vigilantes, conscientes ou mesmo inocentes diante das astúcias da razão. Estamos mais implicados na totalidade e em seus crimes do que podemos imaginar. Levinas recusa a idolatria hegeliana do Estado, mas reconhece, com Hegel, que só há justiça no interior da totalidade. Neste caso, é forçoso perguntar: que significa pensar o político para além das astúcias da razão?

\footnotetext{
${ }^{1}$ HEGEL, G.W.F.- Filosofia da História. Trad. Maria Rodrigues e Hans Harden, Brasília: Editora UNB, 2008. p. 31-32.

${ }^{2}$ Cf. Id.HEGEL, G.W.F.- Principes de la philosophie du droit. Trad. Robert Derathé, Paris: Vrin, 1986. $\S 118$, p. 157.

${ }^{3}$ Ibid., $\S 119$, p. 160 , nota 18.
} 


\section{Como a vontade subjetiva entra na astúcia da razão}

Comecemos pela tese hegeliana sobre a política e a história. Os indivíduos são apenas meios para que a efetividade de um Estado possa realizar-se. A racionalidade da história, por sua vez, é inseparável das paixões individuais, por vezes contrárias ao bom senso e à moralidade. O Espírito se beneficia das paixões humanas para se conhecer a si mesmo. Os seres humanos morrem, mas o Espírito, não. Em seu existir finito, os indivíduos querem, desejam, vivem, afirmam seus propósitos, agindo a partir de interesses que podem muito bem contrastar com o bem comum, com a moralidade, com as leis de um país. Os indivíduos, com suas paixões, podem tanto se realizar egoisticamente quanto servir como um meio para a realização de uma substancialidade que os ultrapassa, que se beneficia deles para vir a si, para se conhecer, para afirmar-se como liberdade ${ }^{4}$.

Na perspectiva hegeliana, a razão rege a história. Para tanto, a universalidade deve envolver-se com algo de particular. As paixões humanas, por sua vez, ao ligarse ao divino, trazem-no necessariamente para a imanência do mundo. Sem os fins particulares, o universal não poderia se realizar. Mais ainda: o universal encontra-se, ele próprio, nesses fins. Eis a síntese entre liberdade e necessidade, entre tempo e eternidade, entre contingência e o absoluto. A história universal é marcada por oposições, conflitos, tensões. Não há paz nem felicidade na história, apenas páginas em branco, períodos dos acordos ${ }^{5}$. Os indivíduos, enquanto meios, vivem suas paixões, mas podem contribuir para a construção de um monumento que está muito além de suas intenções, de suas expectativas, de seus projetos. Nas palavras de Hegel:

Na história universal, resulta das ações humanas algo além do que foi intencionado. Por meio de suas ações os seres humanos conseguem o que querem de imediato. Porém, ao concretizar os seus interesses, eles realizam algo mais abrangente; algo que se oculta no interior de suas ações, mas que não está em sua

\footnotetext{
${ }^{4}$ Cf. HEGEL, 2008, p. 29.

${ }^{5}$ Cf. Ibid., p. 30.
} 
consciência ou em sua intenção (...). A ação imediata pode conter algo além do que está na vontade e na consciência do autor ${ }^{6}$.

A verdade da ação ultrapassa o que fora nela intencionado ${ }^{7}$. É assim que um agente histórico de alta importância pode, com sua ambição pessoal, realizar aquilo que o espírito de uma época exigia dele ${ }^{8}$. Suas ações particulares continham instintivamente uma vontade muito além de sua própria, aquela do espírito universal. Imerso em conflitos, atravessado por paixões, exposto a perigos um indivíduo pode aproximar o particular do universal, mantendo a ideia preservada, intocada, imperecível. Eis a astúcia da razão: os indivíduos são meios para que uma verdade universal venha à tona, compensando todas as perdas e danos, isto é, o sacrifício e o abandono de muitos em benefício daquilo que realmente importa: a ideia ${ }^{9}$.

Ao enfatizar a liberdade do espírito mediada pelas paixões e volições humanas, Hegel não deixa de lado a pergunta pelo fim dos próprios indivíduos. Eles também podem desfrutar a liberdade. Como? Limitando a arbitrariedade do querer. É preciso que a vontade particular e abstrata seja suprimida para fazer sua entrada na história, isto é, na vontade objetiva e universal. Ou ainda: o indivíduo pode participar de uma totalidade ética chamada Estado, que não é outra senão o interesse absoluto da razão. O Estado é, por via de consequência, a finalidade absoluta, a própria realização da liberdade. Ele deve existir por si mesmo e, ao mesmo tempo, fornecer ao ser humano todo o seu valor. Que se deve entender por verdade? Nada

\footnotetext{
${ }^{6}$ HEGEL, 2008, p. 31.

${ }^{7} \mathrm{Na}$ Filosofia do Direito, Hegel afirma: "O que está em jogo, aqui, não é a ação isolada, é o todo que não se relaciona àquilo que há de determinado nesta ação particular, mas à natureza universal desta ação. A passagem do projeto à intenção consiste no seguinte: não devo conhecer unicamente minha ação singular, mas também o aspecto universal que ela comporta (HEGEL, 1986, § 118, p. 158, nota 18).

${ }^{8} \mathrm{O}$ raciocínio de Hegel pode ser assim resumido: um sujeito moral qualquer deve estar ciente de que suas ações podem levar a consequências imprevisíveis, e por isto, mesmo não sendo diretamente culpado por um acontecimento desencadeado por seus atos, tal sujeito poderá ser indiretamente imputado (dolo indireto). Ele está exposto, assim, a algo de não particular, no caso, às leis de seu país. Mas o que interessa a Hegel é a dimensão filosófica deste caráter contingente da vontade, vale dizer, é a supressão do caráter contingente, formal e subjetivo da vontade pelo universal (politicamente, pelo Estado) (cf. HEGEL, 1986, § 132, p. 170 e ss.).
}

${ }^{9}$ Cf. HEGEL, 2008, p. 35. 
mais que a unidade da vontade universal com a vontade subjetiva, vale dizer, o Estado como ideia divina na qual a oposição entre liberdade e necessidade simplesmente se dissolve ${ }^{10}$. Que é a vontade boa? Aquela que suprimiu a vontade subjetiva e abstrata, tornando-se vontade conforme ao conceito ${ }^{11}$. O mal é a vontade particular a ser suprimida, mas, na medida em que torna possível a passagem da moralidade à eticidade, o mal é sempre necessário. O que interessa observar, aqui, é isto: o mal está justamente em se limitar a querer o bem, em agir com boa intenção, ou seja, em procurar levar em conta apenas o aspecto abstrato da vontade ${ }^{12}$. Guardemos esta tese lapidar, pois ela terá um enorme impacto sobre o pensamento de Levinas.

Impacto significativo terá, igualmente, o seguinte argumento: a filosofia hegeliana da história afirma que o pensamento universal não pode se separar do individual. Certo, na perspectiva hegeliana o individual só ganha inteligibilidade plena pelo pensamento universal, mas a universalidade não será algo desvinculado do histórico, do temporal, das contingências. Ele será um universal concreto ${ }^{13}$. Uma particularidade que não reconhecesse sua subordinação à inteligibilidade do Todo, seria uma rebeldia abominável. Rebeldia que Hegel identifica na separação do universal e do particular presente no judaísmo. O ato de separação em relação a tudo o que nos envolve é o ato fundacional do judaísmo, segundo Hegel ${ }^{14}$.

Daí poder-se dizer que, no âmbito da razão na história, não faz muito sentido se preocupar com a bondade ou a maldade de nosso querer e de nosso agir. Os interesses dos indivíduos, por mais egoístas que sejam, podem contribuir com a determinação da vontade, com a obra da razão. Mas há uma afirmação de Hegel que coloca Levinas muito próximo do filósofo alemão: "O ato (die Tat) produz uma mudança na realidade existente, de tal modo que a vontade se sente responsável por

\footnotetext{
${ }^{10}$ Cf. HEGEL, 2008, p. 39-40.

${ }^{11}$ Cf. HEGEL, 1986, § 139, p. 177.

${ }^{12}$ Ibid., p. 183.

${ }^{13}$ LEVINAS,E.- Difficile liberté, Paris: Albin Michel, 1995. p. 304.

${ }^{14}$ Cf. Ibid., p. 306.
} 
isso, na medida em que o predicado abstrato daquilo que é meu é introduzido na realidade assim modificada" ${ }^{15}$. Ou seja, sou responsável por aquilo que meu ato intencionou e trouxe à realidade (prejudiquei alguém para obter uma vantagem pessoal, por exemplo), e, além disso, sou culpado pelo que este mesmo ato desencadeou para além de minhas próprias intenções (várias pessoas, que não estavam implicadas diretamente, foram prejudicadas por aquilo que fiz). Devo suportar as consequências que ultrapassam as intenções de meu ato ${ }^{16}$.

\section{Carrego uma falta que não se reflete em minhas intenções}

Entremos na fenomenologia de Levinas. Na perspectiva hegeliana, o mal é a particularidade que ainda não reconheceu o universal. Considerada em si mesma, a vontade subjetiva (natural) não é boa nem má: é uma espécie de vontade inocente. A pergunta é: por quê? De onde vem a culpabilidade? Do ponto de vista fenomenológico, as subjetividades humanas só podem se relacionar ao universal graças à intersubjetividade, isto é, do reconhecimento de que estamos diante de outras consciências, de outros seres humanos, de liberdades exteriores à nossa. Não é diante desses outros que podemos ser culpados ou inocentes? Hegel diria que sim, mas apenas porque estamos imersos numa ordem sócio-política com suas leis e costumes, isto é, numa totalidade cultural. Ocorre que, para Levinas, esta imersão depende de uma situação anterior e irredutível à ordem político-social. "A relação do eu com a totalidade é uma relação com os seres humanos dos quais reconheço o rosto. Em relação a eles sou culpado ou inocente. A condição do pensamento é uma consciência moral"17.

O que significa, para Hegel, que as ações podem ter consequências não previstas pelo que fora intencionado pela consciência? Que participamos de uma

\footnotetext{
${ }^{15}$ HEGEL, 1986, § 115, p. 157.

${ }^{16}$ Cf. Ibid., $\S 118$, p. 158.

${ }^{17}$ LEVINAS, E.- Entre Nós. Ensaios sobre a alteridade. Trad. Pergentino S. Pivatto (Coord.), Petrópolis: Vozes, 1997. p. 39.
} 
contabilidade racional que nos ultrapassa como indivíduos, contabilidade essa que confere substancialidade a nossas ações. "A natureza do homem consiste, com efeito, em ser essencialmente um ser universal, e não um ser abstrato, limitado ao instante presente e separado do saber" ${ }^{18}$. Ora, quem afirma isto é o sujeito humano singular, aqui e agora, numa situação particular. Se o ser humano só é humano quando relacionado ao universal, como ele toma consciência disto? Tal é a pergunta de Levinas. Que significa nossa relação de subjetividades contingentes com a contabilidade racional, com a totalidade? Só sabemos que nos relacionamos com a totalidade porque, de algum modo, já nos percebemos fora dela. Posso ser culpado ou inocente antes mesmo de entrar na contabilidade do universal. Sei que posso lesar alguém, aqui e agora. Meu querer e meu agir podem ferir alguém. É diante de outrem que sou culpado ou inocente. Mas, entre dois indivíduos, a desculpa é sempre possível. Assim, só posso me sentir responsável pelas repercussões de meus atos, para além do que intencionei, porque sou capaz de visualizar situações que vão além da dualidade do eu e do outro. Reconheço minha culpa pelo que me ultrapassa na medida em que, para além do aqui e agora de minha relação com alguém, sei que me relaciono a um terceiro homem ${ }^{19}$, a outros seres humanos. É esse reconhecimento, com efeito, que me fará acertar as contas com o universal, e não o contrário!

Ao realizar uma fenomenologia do face a face, Levinas compreende que o âmbito astucioso da razão jamais poderia encobrir o fato de que "o pensamento começa com a possibilidade de se conceber uma liberdade exterior à minha" ${ }^{20}$. A relação entre liberdades, isto é, entre consciências separadas umas das outras torna possível um tipo de culpabilidade que não começa do acerto de contas com o universal, pois é a relação a outrem que nos insere na ordem da razão. Mas, repetimos a pergunta: de onde vem a culpabilidade? Do fato de que não posso controlar os danos que terei causado e causarei a indivíduos que não estão diante de

\footnotetext{
${ }^{18}$ HEGEL, 1986, § 132, p. 171.

${ }^{19}$ Cf. LEVINAS, 1997, p. 40.

${ }^{20}$ Ibid., p. 39.
} 
mim, que possivelmente nunca verei. A relação com outrem me faz ver que a violência que cometo, aqui e agora, pode ser perdoada pelo outro agredido, presente diante de mim, mas este possível perdão não me absolve dos crimes cometidos no interior da totalidade, crimes esses nos quais estamos envolvidos ou implicados.

Devo reconhecer que minhas ações têm sempre consequências para além da relação que estabeleço com outrem (numa relação que se dá fora da totalidade). Minhas ações, que estão relacionadas a este indivíduo, aqui e agora, já ultrapassam a própria relação dual entre nós. Elas têm implicações para pessoas que não fazem parte do contexto em que me encontro, neste momento, diante de outrem. Viver em sociedade implica o fato de que a vontade corre sempre o risco de se alienar de si mesma, encontrando-se comprometida com aquilo que lhe escapa como intencionalidade. Não posso fugir da culpabilidade que carrego em mim como subjetividade que tomou consciência do imprevisível de suas ações. $O$ fundo hegeliano da questão é notável:

A significação objetiva de minha ação sobrepuja sua significação intencional: não sou mais, propriamente falando um eu; carrego uma falta que não se reflete em minhas intenções. Eu sou objetivamente culpado, e disto minha piedade não me pode purificar $^{21}$.

Para Hegel, com efeito, a culpabilidade individual de alguém se dá quando seu querer contrasta com a ordem social, com as leis, com os costumes. Eis o indivíduo responsável por seus atos num contexto de regras e normas que ultrapassam a relação entre aquele que lesa e o que é lesado. Ora, na perspectiva levinasiana o débito de um indivíduo em relação a outro começa antes mesmo de uma moralidade dada, transmitida, instaurada. Por isso, a culpabilidade diante de outrem se estende para além do face a face, mostrando minha responsabilidade por tantos rostos que não fazem parte de minha circunstância atual, ou ainda: fazendo ver que minhas ações podem lesar o terceiro homem, aquele em quem nem mesmo

\footnotetext{
${ }^{21}$ LEVINAS, 1997, p. 42.
} 
pensava quando realizava a ação. As consequências imprevisíveis de minhas ações colocam o problema da consciência como sendo, de saída, um problema ético e a justiça, por sua vez, como inquietação diante da possibilidade de se provocar um ferimento em pessoas que não estão diante de mim, mas que sofrem as consequências danosas de minha boa consciência. Pela citação que segue, pode-se ver o quanto Levinas está próximo e, ao mesmo tempo, distante de Hegel:

A falta social é cometida sem que eu o saiba, em relação a uma multiplicidade de terceiros que eu não olharei jamais de frente (...). A intenção não poderia acompanhar o ato até seus prolongamentos últimos, contudo, $\mathrm{o}$ eu se sabe responsável por estes prolongamentos ${ }^{22}$.

O ser humano é um animal político na medida em que é capaz de reconhecer sua responsabilidade pelo que ultrapassa sua boa consciência visando um bem. Toda aspiração à inocência já supõe, segundo Levinas, o eu como singularidade insubstituível, a qual será lançada numa ordem estranha, guiada não por boas intenções, mas por uma astúcia que não tem olhos para os bons sentimentos ou pela correção moral. Minha consciência como que me escapa, eis o impasse do liberalismo ${ }^{23}$.

Somos, então, uma máscara em meio a outras máscaras, num contexto em que não há nenhum cogito, vale dizer, nenhuma palavra e nenhum gesto imunes à suspeição. Tudo o que dizemos ou intencionamos pode ser investigado pelos saberes e métodos constituídos: psicanálise, sociologia, linguística, etc. Não somos o que temos consciência de ser, e sim "o papel que exercemos em um drama do qual não somos mais os autores" ${ }^{24}$. E a singularidade diante de outra singularidade, e a relação entre pessoas? Esta pergunta já depende de uma consciência que despertou para sua responsabilidade, isto é, de um eu que se encontra fora da ordem racional. O que

\footnotetext{
${ }^{22}$ LEVINAS, 1997, p. 45.

${ }^{23}$ Cf. Ibid., p. 47.

${ }^{24}$ Ibid., p. 46.
} 
caracteriza o sujeito não é o poder de se conhecer a si mesmo, mas o poder de falar, de responder. A esfera intersubjetiva é constituída por singularidades que se encontram fora da lógica do Todo, que podem ver e questionar a astúcia da razão ocorrendo dentro de tal lógica. Eis por que, afirma o filósofo, "a totalidade não se reduz a um reino de fins" ${ }^{25}$. Por quê? Porque a totalidade não é constituída entre razões, mas entre subjetividades vivas, singularidades humanas irredutíveis.

Mas, enquanto animal político, enquanto relacionado àqueles que não estão diante de mim e que constituem a totalidade, devo reconhecer, com Hegel, que minha vontade subjetiva está imersa num destino que a ultrapassa, no caso, a própria história. Meu querer se aliena, se separa de minha consciência às voltas com seu objeto, no caso, um suposto bem. Nós entramos na história por nossos atos volitivos, mas a história despreza essa referência subjetiva, ela não pode vê-los nem os reconhecer. Esta, por assim dizer, traição da vontade por si mesma é a condição para que algo como a sociedade exista, para que uma comunidade de liberdades seja constituída, mas é também a confirmação de que, na totalidade, a injustiça é inevitável. O outro como terceiro está sujeito à manipulação, à objetivação, às transações econômicas. Compro, exploro, faço negócios sem me preocupar com as consequências desses atos. Suponho-me inocente, dotado de méritos; percebo-me como um bom cidadão. Mas, na medida em que somos subjetividades vivas, somos também consciências que podem julgar a contabilidade histórica, econômica, objetiva. O ser humano, afirma Levinas, "é um poder de julgar a história"26. Dito de outro modo, o ser humano pode, de certo modo, dominar a totalidade na medida em que se eleva à consciência da justiça.

\section{Suspendendo a consonância com as violências do mundo}

\footnotetext{
${ }^{25}$ LEVINAS, 1997, p. 51.

${ }^{26}$ Ibid., 56. A nosso ver, esta tese é retomada pela obra Totalidade e Infinito de modo notável: "A história é atravessada pelas rupturas da história", isto é, pelos "juízos que se voltam para ela" (...). "Quando o homem aborda outrem verdadeiramente, ele é arrancado da história" (LEVINAS, E.Totalité et Infini, La Haye: Martinus Nijhoff, 1974. p. 23).
} 
Enquanto capaz de dominar a totalidade, de se ver fora dela, o existente humano é aquele que se descobre responsável pelo que se passa no interior da lógica do Todo, pois, não fosse assim, nosso clamor por justiça seria uma palavra vazia, sem efeito algum. Nós nos colocamos fora da contabilidade racional e, ao mesmo tempo, a servimos na medida em que lutamos por justiça. "A totalidade é constituída pela violência e pela corrupção" ${ }^{27}$. Nas lutas mortais entre liberdades, como introduzir a igualdade, sobretudo em sentido econômico? A justiça nasce fora das astúcias da razão (no encontro face a face com outra liberdade), mas não pode manter-se fora das próprias relações econômicas que que predominam num mundo entregue ao jogo e à exploração.

Vivemos num mundo supostamente liberal e democrático. Nele, sempre podemos agir buscando realizar o bem. Ao mesmo tempo, tomamos consciência de que estamos envolvidos em obscuridade, que somos objetivamente culpados por tantos sofrimentos e injustiças. Uma boa imagem de nós mesmos talvez seja a daqueles habitantes das "cidades-refúgio ${ }^{28 "}$, instituídas no contexto bíblico. Alguém que comete um homicídio acidentalmente e que, ao fazê-lo, desperta o espírito de vingança. Alguém que, enquanto inocente subjetivamente, mas culpado objetivamente, deve ser protegido. Afirma Levinas: "A imprudência, a falta de atenção, limita nossa responsabilidade? Será que somos conscientes o bastante, vigilantes o bastante, homens suficientemente homens? É preciso cidades-refúgio ${ }^{29}$,

\footnotetext{
${ }^{27}$ LEVINAS, 1997, p. 63.

${ }^{28}$ No estudo talmúdico em questão, Levinas menciona Números, 35 , onde se encontra a mensagem divina a Moisés sobre tais cidades de refúgio, nas quais homicidas que tiverem matado alguém involuntariamente devem ser acolhidos e protegidos. Cidades que servem de asilo contra o vingador de sangue.

${ }^{29}$ Hegel lembra de algo semelhante, embora entre os antigos gregos. Os antigos não davam a mesma importância que os modernos dão ao elemento subjetivo, à responsabilidade. Édipo, por exemplo, mata o pai sem saber, isto é, ele não é responsável subjetivamente pelo ato. Eis por que, afirma Hegel, os antigos possuíam asilos para proteger esses indivíduos da vingança que recaía sobre eles (cf. HEGEL, 1986, § 117, p. 157, nota 14).
} 
onde esses meio-culpados e esses meio-inocentes possam permanecer protegidos da vingança" ${ }^{\prime 30}$.

Nossa sociedade se diz civilizada, mas é carente de igualdade e de justiça social rigorosa. No interior dessa sociedade, podemos sempre ser culpados da agonia de alguém, em algum lugar, tendo em vista as vantagens que podemos ter sobre outros. Daí a pergunta: "não haveria, em alguma parte do mundo, guerras e morticínios que são a consequência dessas vantagens?"31. O judaísmo, que Hegel recalcou, é resgatado por uma fenomenologia da consciência moral, consciência entendida como liberdade (epoché) em relação à história, como inquietude pela justiça, para além da própria ideia de cultura (vinculação à terra e ao local, arquitetura, artes, etc. $)^{32}$. O humano, portanto, é um modo de existir caracterizado pela liberdade, e a subjetividade, por sua vez, se manifesta como "vida que não está nunca em acordo com as violências do mundo" ${ }^{33}$. Epoché levinasiana da astúcia da razão. "A razão apenas ludibria os homens (ruse avec eux). Eles acreditam pensar quando, na verdade, realizam aquilo que a razão desenhou"34.

Há homicídios involuntários por toda parte. Temos força para manter a boa consciência, mas não para evitar a traição da vontade por nossos próprios atos. Ora, a realidade não é tão transparente assim. Nossos sentimentos estão misturados. Mesmo o ódio pode ser tomado por fraternidade. Tudo se passa como se tivéssemos perdido o chão. Onde, uma base segura, uma orientação em meio ao fluxo

\footnotetext{
${ }^{30}$ LEVINAS, E.- L'au-delà du verset, Paris: Minuit, 1982. p. 56.

${ }^{31}$ Cf. Ibid., p. 56.

${ }^{32}$ Cf. LEVINAS, 1995, p. 41.

${ }^{33}$ LEVINAS, 1982, p. 62.

${ }^{34}$ LEVINAS, 1995, p. 74. Na nossa perspectiva, Derrida descreve com maestria esta situação no mundo contemporâneo. Na sociedade de mercado, aquela que se intitula liberal, democrática, atenta ao estado de direito, é a mesma que faz e deixa morrer de fome e de doença, sem nenhuma culpa aparente, centenas de milhões de crianças. Que tribunal jurídico ou moral aparece para realizar o julgamento deste sacrifício do outro? "Uma tal sociedade não apenas participa desse sacrifício incalculável, mas até mesmo o organiza. O bom funcionamento de sua ordem econômica, política, jurídica, o bom funcionamento de seu discurso moral e de sua boa consciência pressupõem a operação permanente desse sacrifício" (DERRIDA, J.- Donare la morte. Trad. Luca Berta, Milano: Jaca Book, 2002. p. 118).
} 
interminável do devir? A Torá significa, para Levinas, a consciência voltada ao estudo, a vigilância, o despertar. Extrema consciência, nas palavras do filósofo. Graças a essa vida dedicada ao estudo e à inteligência, deixamos de ser arrastados pelos acontecimentos, suspendemos nossa cumplicidade com as violências do mundo. Ela permite pôr em questão a pretensão de que a reta consciência e a boa vontade, bem como nossa atenção ao real, seriam suficientes para manter a vida consciente em estado de vigília ${ }^{35}$.

Eis que, na sociedade liberal, o vingador de sangue sempre pode irromper em nossas vidas, ele circula em torno de nós. Bem sabemos que sua cabeça está quente. Somos "culpados bem-intencionados" diante de tantas agitações sociais, de cóleras populares, do espírito de revolta de tantos jovens, da delinquência nas periferias, etc. Tudo isto como resultado do desequilíbrio social em que nos encontramos. O filósofo entende que nós próprios, bons cidadãos do mundo burguês, vivemos numa espécie de cidade-refúgio. Enquanto meio-culpados e meio-inocentes, vivemos nessas cidades como seres exilados. Daí a pergunta cortante: "Nossa humanista e brilhante civilização não é um pouquinho hipócrita, bastante insensível à cólera desarrazoada do vingador de sangue, incapaz de restabelecer o equilíbrio?"36. Para dizer fenomenologicamente, a passagem do não-intencional ao intencional, neste caso específico, é realmente sensível, marcada por um claro-obscuro que dificulta a tomada de consciência de nossa responsabilidade.

Levinas propõe uma civilização política atenta à fragilidade da vontade. Civilização aspirando a construir uma organização político-social sempre às voltas com aquilo que a vontade pode provocar a despeito de suas boas intenções. Civilização capaz de responder aos apelos daqueles que tiveram sua singularidade negada em nome da tirania ou neutralidade do universal ${ }^{37}$. Não poderiam as cidadesrefúgio ser o emblema de um novo Ethos político-cultural?

\footnotetext{
${ }^{35}$ Cf. LEVINAS, 1982, p. 57.

${ }^{36}$ Ibid., p. 57.

${ }^{37}$ Cf. LEVINAS, 1974, p. 219 e ss. Hegel nos ajuda a compreender esta negação. Muitos povos, pensa ele, não fazem parte da história universal. Os africanos, por exemplo, não tiveram a mínima ideia do
} 
Derrida $^{38}$ parece ter se inspirado em Levinas quando, numa de suas conferências, sustentou que as cidades-refúgio são independentes do Estado, que elas poderiam se espalhar pelo mundo, acolhendo, a partir de formas de solidariedade por vir, imigrados, exilados, refugiados, deportados, sem-pátrias, etc. Cidades que teriam o desafio de transformar e refundar o modo como as cidades se ligam ao Estado, de propor uma nova ética, pautada pelo acolhimento de tantas vítimas anônimas de violências em escala mundial, espalhadas pelo mundo. Vítimas que não encontram, por parte dos Estados, uma proteção satisfatória ou minimamente humana. Esta política inovadora supõe um conceito de cidade caracterizado pela possibilidade de, quando for o caso de hospitalidade e de acolhimento, elevar-se acima dos Estados-Nação. O desafio mais premente é este: "como ajudar os hóspedes das cidades-refúgio a reconstruir, através do próprio trabalho ou atividades criativas, um tecido vivo e durável nesses novos lugares, até mesmo numa língua nova?”39.

Eis que as cidades de refúgio podem ser o emblema de um novo ethos políticocultural, de uma nova cosmopolítica. Segundo Derrida, Levinas está orientando nossos olhos para os dias de hoje, em Israel, na Europa, na Ásia. Ele nos mostra os refugiados de toda sorte, imigrantes, exilados, etc. Ele nos mostra a universalidade humana, a hospitalidade humana desenraizada. Ou seja, quando um povo aceita receber aqueles que vêm se instalar junto a ele, temos aí a humanidade do homem ${ }^{40}$. Nas palavras de Catherine Chalier: "É preciso construir um mundo em que cada um

que seja a essência do homem. Uma objetividade fixa (leis, por exemplo) está longe de seus pensamentos (cf. HEGEL, 2008, p. 82 e ss.). Há povos que sucumbem tão logo o "espírito" deles se aproxima, tais como mexicanos e peruanos (Ibid., p. 74). São, por assim dizer, os excluídos da contabilidade da razão. Estão fora da totalidade.

${ }^{38}$ Trata-se de um escrito que Derrida enviou a um Congresso sobre as cidades-refúgio, junto ao Conselho de Europa, em Estrasburgo, sob a iniciativa do Parlamento Internacional dos Escritores, em 1996. O foco era o apelo, dirigido às cidades europeias no intuito de se constituir uma rede de cidades-refúgio.

39 DERRIDA, J.- Cosmopoliti di tutti i paesi, ancora um sforzo! Trad. Bruno Moroncini, Napoli: Cronopio, 1997a. p. 22.

${ }^{40}$ Cf. DERRIDA, J.- Adieu à Emmanuel Levinas, Paris: Galilée, 1997b. p. 120. 
possa viver, em especial o estrangeiro, a viúva e o órfão ${ }^{41}$. A interioridade moral não basta, pois ela é impotente para defender aqueles que sofrem com as injustiças e as mazelas sociais" ${ }^{42}$. O judaísmo, entendido como não-coincidência com o seu tempo, enquanto "vida que não está nunca em acordo com as violências do mundo", está sempre a nos dizer que é preciso cuidar para que a política não seja entregue a si mesma.

Resumamos o percorrido. A vontade subjetiva, tal como Hegel a entende, é má enquanto não for suprimida pelo conceito forte de vontade. "Pode-se então concluir que se limitar a querer o bem e, no caso de uma ação, se limitar a ter uma boa intenção é, precisamente, o mal, pois o bem é aspirado apenas de maneira abstrata (...)" ${ }^{43}$. A posição de Levinas, embora consciente da lição de Hegel sobre a insuficiência da moral subjetiva, considera a mesma questão, mas numa outra perspectiva. A vontade subjetiva é enganosa e perniciosa exatamente porque é cúmplice da totalidade no sentido hegeliano. Ela é má porque inconscientemente cúmplice da causalidade e das violências do mundo. Assim, questionar a moral subjetiva, formal, abstrata é paradoxalmente lutar contra a tirania do universal concreto, defensor de todas as tiranias, pai de todo nacionalismo. É sair do sistema pela porta em que se entra nele: a relação do eu com a totalidade. É compreender que o particularismo condiciona a universalidade, mas não é suprimido pela universalidade ${ }^{44}$. Mas não um particularismo qualquer, e sim aquele que aspira a uma sociedade plenamente humana no interior mesmo da história, isto é, "na Jerusalém terrestre, e não num fora de todo lugar, em piedosos pensamentos ${ }^{45}$. A

\footnotetext{
${ }^{41}$ Como quer que seja, proposta que vai à contramão do ideal hegeliano de cultura: "Um povo é moral, virtuoso e forte quando está empenhado na realização de seus grandes objetivos e quando protege a sua obra da violência externa durante o trabalho de dar existência objetiva aos seus propósitos" (HEGEL, 2008, p. 68).

${ }^{42}$ CHALIER, C.- Exposé (sur Éthique et Politique). In: HALPÉRIN, J./HANSSON, N.- Difficile Justice. Dans la trace d'Emmanuel Levinas (Colloque des intellectuels juifs), Paris: Albin Michel, 1998. p. 118.

${ }^{43}$ HEGEL, 1986, §140, p. 182.

${ }^{44}$ Cf. LEVINAS, 1995, p. 39.

${ }^{45}$ LEVINAS, 1982, p. 70.
} 
lição de Hegel foi não apenas muito bem compreendida, mas transfigurada e reorientada graças a uma consciência que não apenas é capaz de se ver fora da totalidade, mas de inquietar-se pela justiça, lutando contra os crimes cometidos no interior desta mesma totalidade.

\section{REFERÊNCIAS}

CHALIER, C.- Exposé (sur Éthique et Politique). In: HALPÉRIN, J./HANSSON, N.- Difficile Justice. Dans la trace d'Emmanuel Levinas (Colloque des intellectuels juifs), Paris: Albin Michel, 1998, p. 112-119.

DERRIDA, J.- Cosmopoliti di tutti i paesi, ancora um sforzo! Trad. Bruno Moroncini, Napoli: Cronopio, 1997a.

DERRIDA, J.- Adieu à Emmanuel Levinas, Paris: Galilée, 1997b.

DERRIDA, J.- Donare la morte. Trad. Luca Berta, Milano: Jaca Book, 2002.

HEGEL, G.W.F.- Principes de la philosophie du droit. Trad. Robert Derathé, Paris: Vrin, 1986.

HEGEL, G.W.F.- Filosofia da História. Trad. Maria Rodrigues e Hans Harden, Brasília: Editora UNB, 2008.

LEVINAS, E.- Totalité et Infini, La Haye: Martinus Nijhoff, 1974.

LEVINAS, E.- L'au-delà du verset, Paris: Minuit, 1982.

LEVINAS, E.- Difficile liberté, Paris: Albin Michel, 1995.

LEVINAS, E.- Entre Nós. Ensaios sobre a alteridade. Trad. Pergentino S. Pivatto (Coord.), Petrópolis: Vozes, 1997. 